\title{
Hydrogen Embrittlement in Al-added Twinning-induced Plasticity Steels Evaluated by Tensile Tests during Hydrogen Charging
}

\author{
Motomichi KOYAMA, ${ }^{1,2) *}$ Eiji AKIYAMA ${ }^{2)}$ and Kaneaki TSUZAKI ${ }^{1,2)}$ \\ 1) Doctoral Program in Materials Science and Engineering, University of Tsukuba, 1-2-1 Sengen, Tsukuba, Ibaraki, $305-8571$ \\ Japan. 2) National Institute for Materials Science, 1-2-1 Sengen, Tsukuba, Ibaraki, 305-0047 Japan.
}

(Received on June 1, 2012; accepted on August 2, 2012)

\begin{abstract}
Hydrogen embrittlement of a Fe-18Mn-0.6C-1.5Al steel was observed in tensile deformation during cathodic hydrogen charging. The fracture mode was quasi-cleavage fracture. The relationship between diffusible hydrogen content and fracture stress was arranged by the power law like that for ferritic and Al-free TWIP steels. The Al addition did not affect the magnitude of the degradation of hydrogen embrittlement property at the same current density in TWIP steels. However, the Al-added steel showed a suppression of hydrogen entry and a larger total elongation in comparison to those of the Al-free TWIP steel in the same environment, although the Al addition decreased fracture stress. The larger elongation is one of the reasons for why the Al addition improves the hydrogen embrittlement property of cup specimens.
\end{abstract}

KEY WORDS: high Mn austenitic steel; twinning-induced plasticity steel; hydrogen embrittlement; tensile testing under hydrogen charging.

\section{Introduction}

Twinning-induced plasticity (TWIP) steels have been recognized as a candidate for high strength automobile materials. ${ }^{1,2)}$ Therefore, hydrogen embrittlement of TWIP steels has recently become a notable research topic. It has been reported in $\mathrm{Fe}-15 \mathrm{Mn}-0.6 \mathrm{C},{ }^{1,3)} \mathrm{Fe}-16 \mathrm{Mn}-0.6 \mathrm{C}$, ${ }^{1,3)} \mathrm{Fe}-$ $17 \mathrm{Mn}-0.6 \mathrm{C},{ }^{1,3)} \mathrm{Fe}-18 \mathrm{Mn}-0.6 \mathrm{C},{ }^{4,5)} \mathrm{Fe}-22 \mathrm{Mn}-0.6 \mathrm{C},{ }^{1,3,6,7)}$ $\mathrm{Fe}-17 \mathrm{Mn}-1.2 \mathrm{C},{ }^{8)}$ and $\mathrm{Fe}-15 \mathrm{Mn}-2 \mathrm{Cr}-0.6 \mathrm{C}^{9)}$ TWIP steels. In contrast, $\mathrm{Fe}-15 \sim 18 \mathrm{Mn}-0.6 \mathrm{C}-1.5 \mathrm{Al}$ TWIP steels did not show any hydrogen embrittlement. ${ }^{1,3)}$ The improvement of the hydrogen embrittlement property seems to emanate from the addition of $\mathrm{Al}$.

Al may improve the hydrogen embrittlement property through the following 1) reduction in residual stress, ${ }^{6)}$ 2) suppression of hydrogen entry, 3) suppression of stress concentration arising from the microstructure e.g. deformation twin and martensite, ${ }^{8)}$ and 4) increase in cohesive energy at crack initiation sites such as grain boundaries. However, it is not clear which of these mechanisms actually improves the hydrogen embrittlement resistance. To clarify this mechanism, we must obtain the quantitative relationship among the parameters affecting the hydrogen embrittlement property, which are hydrogen content, fracture stress, elongation, and experimental conditions such as the current density for hydrogen charging. Then we would understand what Al has changed and how that affects the hydrogen embrittlement resistance.

The conditions for the occurrence of hydrogen embrit-

* Corresponding author: E-mail: KOYAMA.Motomichi@nims.go.jp DOI: http://dx.doi.org/10.2355/isijinternational.52.2283 tlement must be found to obtain the relationships among the parameters that are mentioned above. In the previous studies, ${ }^{4,5,8)}$ we examined the hydrogen embrittlement through the tensile tests during hydrogen charging. This method introduced hydrogen successfully by simple diffusion and the motion of hydrogen-decorated dislocations, and the hydrogen entry induced a clear brittle fracture. We also reported $^{5)}$ that the relationship between diffusible hydrogen content and fracture stress could be arranged by the power law. Hydrogen embrittlement would occur under these previous reported conditions even in the Al-added TWIP steels.

In this paper, the first objective is to find the conditions for the occurrence of hydrogen embrittlement in an Al-added TWIP steel. Then the second objective is to obtain a quantitative relationship among fracture stress, elongation, and diffusible hydrogen content.

\section{Experimental}

A steel with a chemical composition of $\mathrm{Fe}-17.6 \mathrm{Mn}-$ $0.61 \mathrm{C}-1.5 \mathrm{Al}$ (wt.\%) was prepared by vacuum induction melting. The thickness of the steel was reduced from 60 to $2.6 \mathrm{~mm}$ by hot rolling at $1273 \mathrm{~K}$, and subsequently reduced to $1.4 \mathrm{~mm}$ by cold rolling. Then, it was solution treated at $1073 \mathrm{~K}$. All the specimens were cut with spark erosion.

The present experiments were conducted under the same conditions as that of our previous work. ${ }^{5)}$ The tensile specimens had a gauge dimension of $4.0 \mathrm{~mm}$ in width $\times 0.3 \mathrm{~mm}$ in thickness $\times 10 \mathrm{~mm}$ in length with a grip section on both ends to fix in an Instron type machine. The thickness was reduced by mechanical polishing from 1.4 to $0.3 \mathrm{~mm}$. The tensile tests were conducted at an initial strain rate of 
$5.1 \times 10^{-5} \mathrm{~s}^{-1}$. Hydrogen was introduced at current densities of $1,3,5,7$, and $10 \mathrm{~A} / \mathrm{m}^{2}$ in a $3 \% \mathrm{NaCl}$ aqueous solution containing $3 \mathrm{~g} / \mathrm{L}$ of $\mathrm{NH}_{4} \mathrm{SCN}$ at ambient temperature during the tensile tests. Total elongations were determined by measuring the gauge length before and after the tests. All the stress-strain curves were fitted to the measured elongations. A platinum wire was used as the counter electrode. The solution was added continually to cover the gauge part of the sample during the tensile tests. The hydrogen content was measured by a thermal desorption analysis (TDA) from room temperature to $550 \mathrm{~K}$ at a heating rate of $100 \mathrm{~K} / \mathrm{h}$. The diffusible hydrogen content was determined by measuring the cumulative desorbed hydrogen from ambient temperature to $473 \mathrm{~K}$. The diffusible hydrogen is defined as the hydrogen that diffuses at room temperature. It is reported to play a key role in hydrogen embrittlement. ${ }^{10)}$

\section{Results and Discussion}

Figure 1 shows the true stress-strain curves that were obtained at various current densities. The fracture stress decreased while the work hardening behavior did not show any significant change with increasing current density. These trends are similar to those of the $\mathrm{Fe}-18 \mathrm{Mn}-0.6 \mathrm{C}$ steel. ${ }^{5)}$ Hereafter, the $\mathrm{Fe}-18 \mathrm{Mn}-0.6 \mathrm{C}$ and $\mathrm{Fe}-18 \mathrm{Mn}-0.6 \mathrm{C}-$ $1.5 \mathrm{Al}$ steels are called as Al-free steel and Al-added steel, respectively. These results indicate that the introduction of

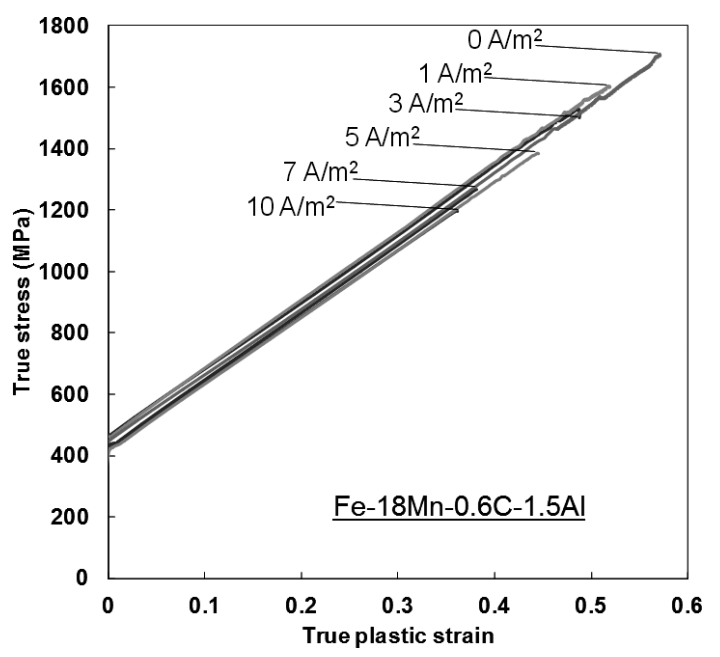

Fig. 1. True stress-strain curves obtained at various current densities in the $\mathrm{Fe}-18 \mathrm{Mn}-0.6 \mathrm{C}-1.5 \mathrm{Al}$ steel. hydrogen did not influence the martensitic transformation and deformation twinning behavior, since martensitic transformation and deformation twinning increase the work hardening rate significantly in TWIP steels. ${ }^{11-14)}$

Figure 2 shows a plot of diffusible hydrogen content against current density. The diffusible hydrogen content increased with increasing current density, and there was a suppression of hydrogen entry in the Al-added steel in comparison to the Al-free steel, ${ }^{5)}$ indicating that the hydrogen trap density of the Al-added steel is lower than that of the $\mathrm{Al}$-free steel. Chun et al. also reported ${ }^{15)}$ that diffusible hydrogen content at the same current density decreased with increasing $\mathrm{Al}$ content in $\mathrm{Fe}-18 \mathrm{Mn}-0.6 \mathrm{C}$ based TWIP steels. According to their experiments and explanation, the decrease in diffusible hydrogen content stems from the decrease in dislocation density by the $\mathrm{Al}$ addition, since dislocations are trapping sites for diffusible hydrogen. From the viewpoint of total elongation, the Al-added steel has a higher resistance to hydrogen embrittlement than that of the Al-free steel at the same current density as shown in Fig. 3(a), but it was lower than that of the Al-free steel at the same diffusible hydrogen content as shown in Fig. 3(b). Note that the mechanical properties against diffusible hydrogen content is overestimated more or less, since the measured diffusible hydrogen includes hydrogen that does not contribute to the hydrogen embrittlement. Therefore, the elongation plotted against diffusible hydrogen content can-

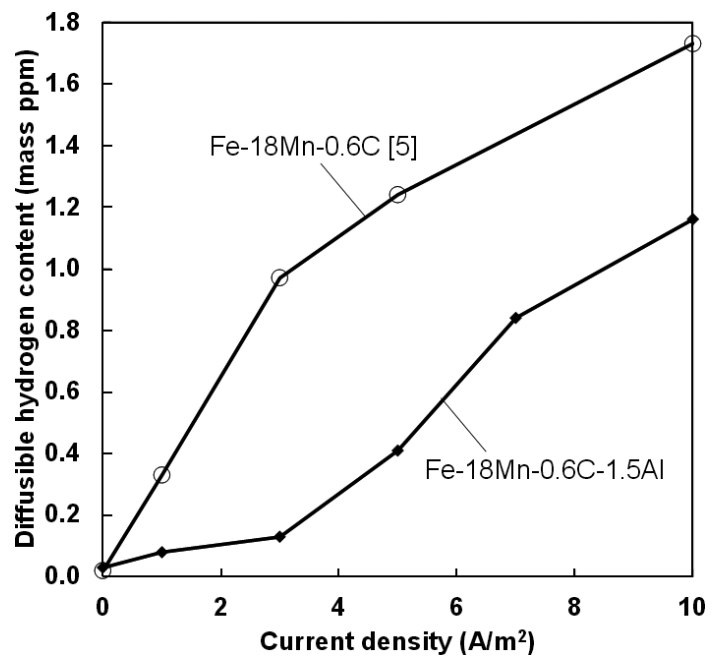

Fig. 2. Diffusible hydrogen content plotted against current density.
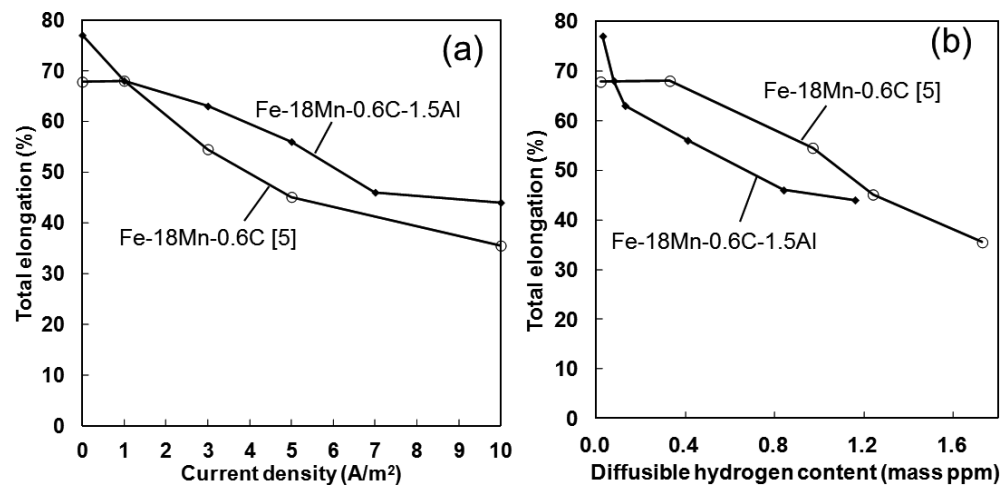

Fig. 3. Total elongation plotted against (a) current density and (b) diffusible hydrogen content. 

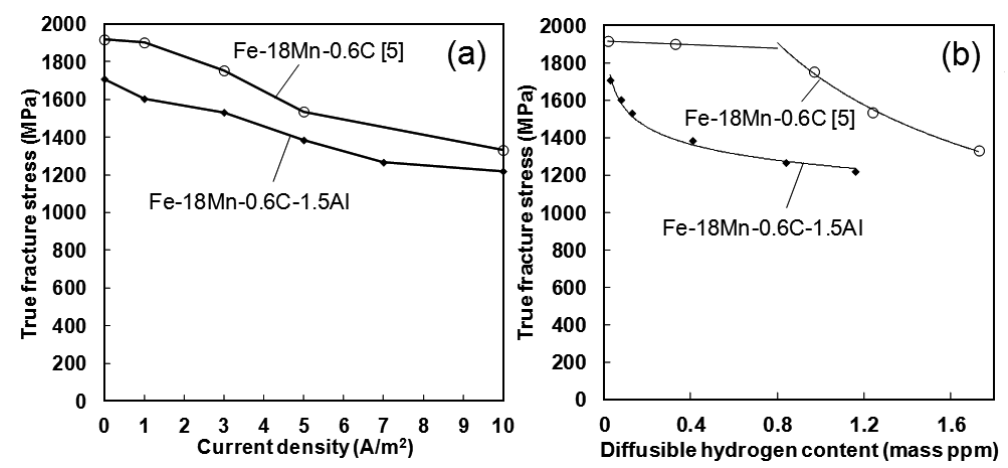

Fig. 4. Fracture stress plotted against (a) current density and (b) diffusible hydrogen content.

not be simply compared between the two steels, because the hydrogen trap density is different between the two steels significantly as can be seen in Fig. 2. The comparison at the same current density that is correspondent to the fugacity of hydrogen of the experimental environment is fairer than that at the same diffusible hydrogen content in steels for the comparison of the susceptibilities to hydrogen embrittlement. The hydrogen embrittlement susceptibility of Al-added steels was reported to be lower than that of Al-free steels when the hydrogen embrittlement susceptibility of TWIP steels was evaluated with cup specimens. ${ }^{1,3,6)}$ Since the cup specimens of various TWIP steels were produced by the same forming process, the hydrogen embrittlement susceptibility was evaluated under a similar strain level. Thus, the higher elongation in the Al-added steel at the same current density corresponds to the lower hydrogen embrittlement susceptibility in Al-added steel specimens with the residual stress such as cup-formed specimens.

In contrast, the fracture stress associated with hydrogen embrittlement in the Al-added steel was lower than that of the Al-free steel at the same current density as well as the same diffusible hydrogen content as shown in Figs. 4(a) and $4(b)$, respectively. We previously reported ${ }^{5)}$ that the relationship between diffusible hydrogen content and fracture stress was arranged by the power law. The present results could also be arranged by the power law as shown in Fig. 5. The quantitative relationship between the diffusible hydrogen content and the fracture stress in the Al-added steel is clearly different from that in the Al-free steel. The cause of the difference also would be associated with hydrogen trap density and hydrogen distribution. The hydrogen trap density and the hydrogen distribution in boundaries such as grain and twin boundaries must change by the Al addition, because the dislocation density ${ }^{15}$ and twin fraction ${ }^{16-18)}$ decrease with increasing Al content. The hydrogen in sites where brittle fracture did not occur does not contribute to the hydrogen embrittlement. For example, intergranular fracture was observed in the Al-free steel. ${ }^{4}$ In this case, hydrogen in grain boundaries is important for the intergranular fracture, though measured diffusible hydrogen content contains the ones in matrix and twin boundaries. The power law between diffusible hydrogen content and fracture stress is maintained both for Al-free TWIP and Al-TWIP with higher and lower hydrogen trap density, respectively. However, the difference in the quantitative relationship does not indicate the difference in the hydrogen embrittlement property directly. Another reason of the difference in Fig. 5 will

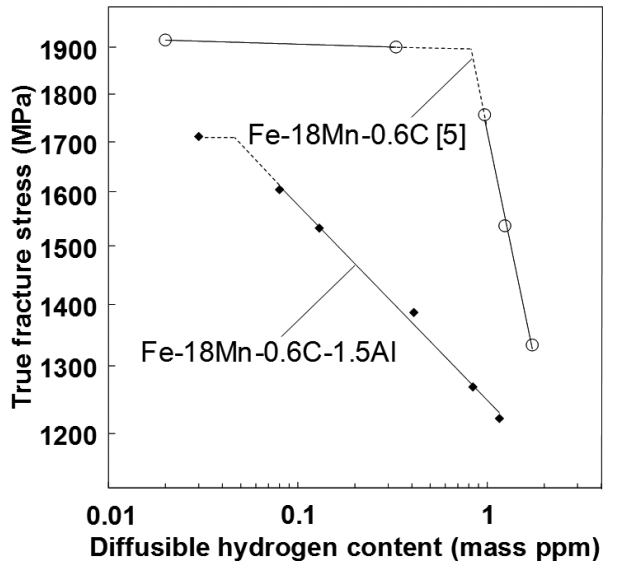

Fig. 5. Double logarithmic plot of diffusible hydrogen content and fracture stress.

be discussed later using the fractographs.

Figures 6 and 7 show the plots of the total elongation and the fracture stress divided by the ones of the no hydrogencharged specimen at various current densities and diffusible hydrogen contents. When the normalized total elongation and fracture stress are plotted against the diffusible hydrogen content as shown in Figs. 6(b) and 7(b), the values of the Al-free steel are higher than those of the Al-added steel. The relationship between normalized total elongation and current density shown in Fig. 6(a) indicates the similar trend of degradation in both steels with hydrogen entry. Also, the normalized fracture stress plotted against current density shown in Fig. 7(a) shows the similar values in both steels. As mentioned before, the decrease of the elongation and fracture stress as a function of the current density is more appropriate for the evaluation of the hydrogen embrittlement susceptibility. Hence, the Al addition did not affect the magnitude of the degradation of hydrogen embrittlement resistance at the same current density.

Fracture mode is an important factor affecting the quantitative relationship between diffusible hydrogen content and fracture stress that was shown in Fig. 5. Figure 8(a) is a fractograph of a specimen without hydrogen charging exhibiting a totally ductile fracture containing dimples. The arrows in Figs. 8(b) and 8(c) indicate that the fracture mode changed from a ductile to a brittle fracture by hydrogen charging. The depth of the brittle fractured part, which is assumed to correspond to the hydrogen-affected zone, increased with increasing current density. Figure 9 is a magnified image of Fig. 8(c), showing a quasi-cleavage fracture 

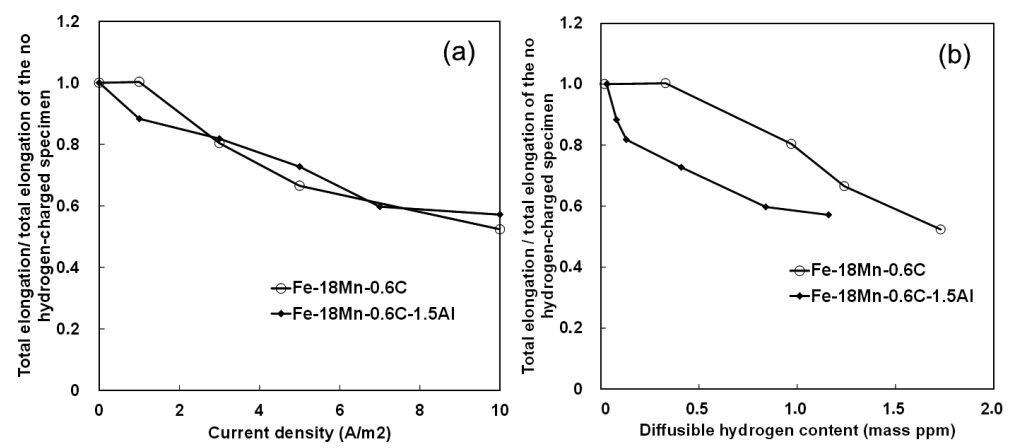

Fig. 6. Total elongation divided by the total elongation of the no hydrogen-charged specimen plotted against (a) current density and (b) diffusible hydrogen content.
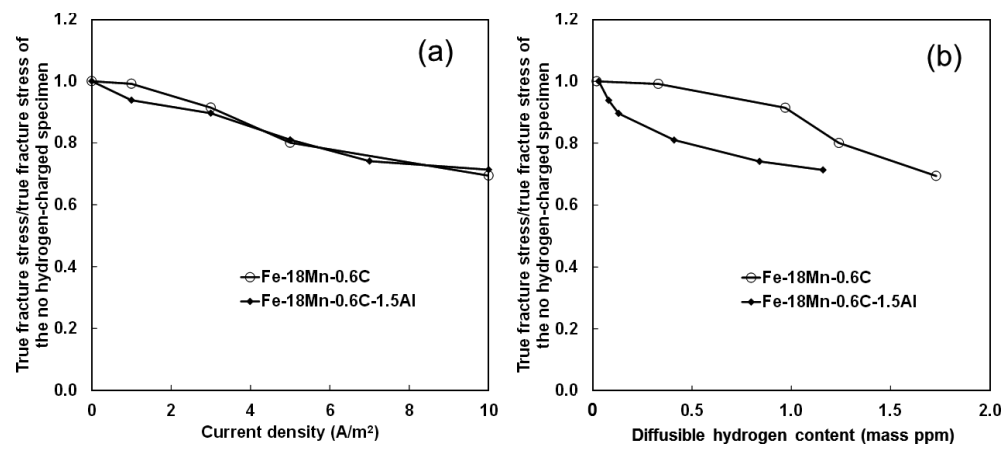

Fig. 7. True fracture stress divided by the true fracture stress of the no hydrogen-charged specimen plotted against (a) current density and (b) diffusible hydrogen content.

(a)

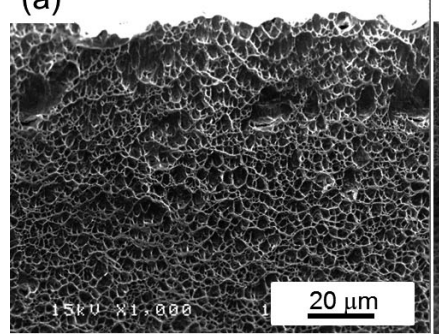

(b)

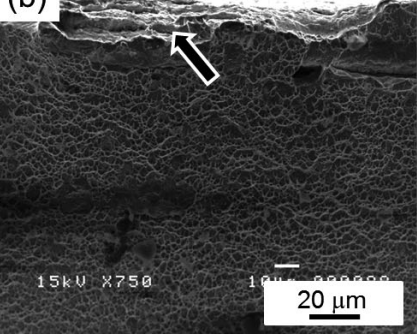

(c)

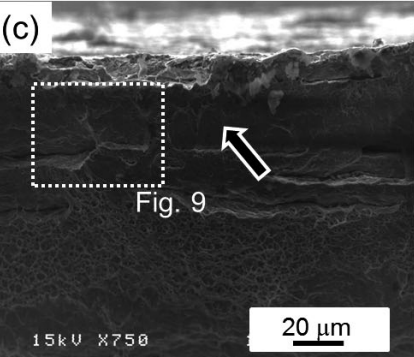

Fig. 8. Fractographs of the $\mathrm{Fe}-18 \mathrm{Mn}-0.6 \mathrm{C}-1.5 \mathrm{Al}$ steel deformed (a) without hydrogen charging and (b) with hydrogen charging at the current density of $3 \mathrm{~A} / \mathrm{m}^{2}$, (c) with hydrogen charging at the current density of $10 \mathrm{~A} / \mathrm{m}^{2}$.

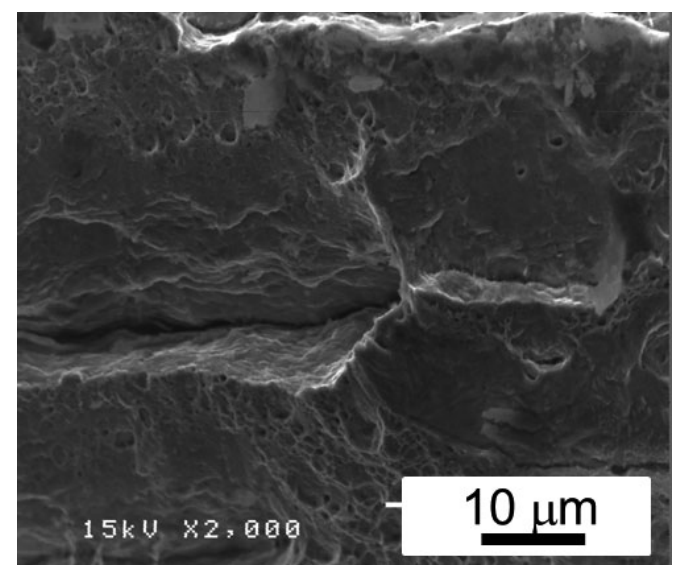

Fig. 9. Magnified image of a section in Fig. 8(c) outlined by the dotted lines.

surface. Since the fracture mode of the hydrogen-charged Al-free steel was intergranular, ${ }^{4,5)}$ the present fracture mode, quasi-cleave fracture, is completely different from that of the Al-free steel. The change in fracture mode must have affected the quantitative relationship between diffusible hydrogen content and fracture stress. A possible reason for the change in fracture mode is suppression of deformation twinning. It is widely accepted that deformation twinning is suppressed by the $\mathrm{Al}$ addition due to an increase in stacking fault energy. ${ }^{16-18)}$ The suppression of deformation twinning reduces local stress at grain boundaries interacting with deformation twins, preventing intergranular cracking that was reported in a previous work. ${ }^{8}$ We believe that the quasicleavage fracture occurred because of the suppression of the intergranular fracture. The region of the brittle fracture near the surface appears flat on the vast area shown in Fig. 8(c). The flat and vast brittle fracture surface would be caused by the following two factors. The first factor is the cleavage fracture plane, which is generally reported to be $\{111\}$ in high Mn steels. ${ }^{19-22)}$ The second factor is the strong $\{111\}$ texture that is known to form along the tensile direction by tensile deformation at ambient temperature. ${ }^{23,24)}$ When the cleavage fracture plane is perpendicular to the tensile direc- 
tion, the fracture occurs along the cleavage fracture plane. If a strong $\{111\}$ texture is formed in the tensile direction (that means that the tensile direction is oriented to $<111>$ after the deformation), the brittle fracture surface apparently becomes flat.

\section{Conclusion}

Hydrogen embrittlement in an Al-added TWIP steel was observed. The relationship between diffusible hydrogen content and fracture stress was arranged by the power law like that of an Al-free TWIP steel. However, the fracture mode of the Al-added TWIP steel was quasi-cleavage fracture, which differed from that of the Al-free TWIP steel. The hydrogen entry was suppressed by the Al addition. The change in the fracture mode and the suppression of the hydrogen entry contribute to improve the elongation at the same experimental environment used for the present study, although the $\mathrm{Al}$ addition decreased fracture stress. The improvement of the elongation contributes to the conventionally-reported enhancement of the hydrogen embrittlement property of cup specimens by the Al addition, since provided strain is approximately the same in an identical size of the cup specimen.

\section{Acknowledgements}

M. K. acknowledges the Research Fellowship of NIMS Junior Researcher (2009-2010) and the Japan Society for the Promotion of Science for Young Scientists (2011). We would also like to acknowledge Dr. Takahiro Sawaguchi for taking part in the discussions during the experiments. POSCO supported this work through the provision of the samples and funding.

\section{REFERENCES}

1) O. Kwon: Proc. of 1st Int. Conf. on High Mn Steels, KIM, Seoul, (2011), CD-ROM.

2) C. Scott, S. Allain, M. Faral and N. Guelton: Rev. Metal. Cah. Inf. Tech., 103 (2006), 293.

3) B. C. De Cooman, K-G. Chin and J. Kim: High Mn TWIP Steels for Automotive Applications, New Trends and Developments in Automotive System Engineering, ed. by M. Chiaberge, InTech, Rijeca, Croatia, (2011), ISBN: 978-953-307-517-4.

4) M. Koyama, E. Akiyama and K. Tsuzaki: Corros. Sci., 54 (2012), 1.

5) M. Koyama, E. Akiyama and K. Tsuzaki: Corros. Sci., 59 (2012), 277.

6) K-G. Chin, C-Y. Kang, S. Y. Sin, S. Hong, S. Lee, H-S. Kim, K-H. Kim and N. J. Kim: Mater. Sci. Eng. A, 528 (2011), 2922.

7) M. Koyama, E. Akiyama and K. Tsuzaki: Scr. Mater., 66 (2012), 947.

8) M. Koyama, E. Akiyama, T. Sawaguchi, D. Raabe and K. Tsuzaki: Scr. Mater., 66 (2012), 459.

9) Y. S. Chun, J. S. Kim, K.-T. Park, Y.-K. Lee and C. S. Lee: Mater. Sci. Eng. A, $\mathbf{5 3 3}$ (2012), 87.

10) K. Takai and R. Watanuki: ISIJ Int., 43 (2003), 520.

11) L. Remy and A. Pineau: Mater. Sci. Eng., 28 (1977), 99.

12) O. Grässel and G. Frommeyer: Mater. Sci. Technol., 14 (1998), 1213.

13) M. Koyama, T. Sawaguchi, T-K. Lee, C-S. Lee and K. Tsuzaki: Mater. Sci. Eng. A, 528 (2011), 7310.

14) I. Gutierrez Urrutia and D. Raabe: Acta Mater., 34 (2011), 211.

15) Y. S. Chun, K.-T. Park and C. S. Lee: Scr. Mater., 66 (2012), 947.

16) J. Kim, S.-J. Lee and B. C. De Cooman: Scr. Mater., 65 (2011), 363.

17) J. Kim and B. C. De Cooman: Metall. Mater. Trans. A, 42A (2011), 932.

18) K.-T. Park, K. G. Jin, S. H. Han, S. W. Hwang, K. Choi and C. S. Lee: Mater. Sci. Eng. A, 527 (2010), 3651.

19) R. L. Tobler and D. Meyn: Metall. Trans. A, 19A (1988), 1626.

20) Y. Tomota and S. Endo: ISIJ Int., 30 (1990), 656.

21) M. Koyama, T. Sawaguchi and K. Tsuzaki: ISIJ Int., 52 (2012), 168.

22) M. Koyama, T. Sawaguchi and K. Tsuzaki: Metall. Mater. Trans. A, (2012), DOI : 10.1007/s11661-012-1220-7.

23 ) D. Barbier, N. Gey, N. Bozzolo, S. Allain and M. Humbert: $J$. Microsc., 235 (2009), 67.

24) J. A. Jiménez and G. Frommeyer: Mater. Charact., 61 (2010), 221 